Aksaray University
Journal of Science and Engineering
e-ISSN: 257-1277
http://dergipark.gov.tr/asujse
http://asujse.aksaray.edu.tr

Research Article

\title{
Investigation of Static and Dynamic Behaviour of Mersin Aksifat Dam
}

\author{
Ayse Bengu Sunbul*
}

Bulent Ecevit University, Department of Civil Engineering, 67100, Zonguldak, Turkey

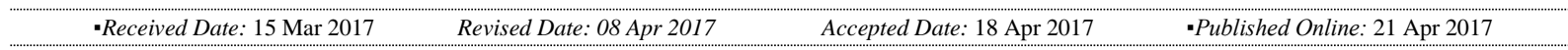

\begin{abstract}
In this study, the settlement behavior of Aksifat concrete faced rock-filled dam was analyzed, during both period of construction and its water retention. In order to determine total displacement and stress distribution, two-dimensional strain analyses were performed using PLAXIS program based on the finite elements method. The material parameters of the dam were obtained from geotechnical reports, literature studies and the well logging data carried out within the scope of the project. The linear elastic material model was preferred for the bedrock in dam modelling, while the Mohr-Coulomb (MC) model was used for the rock fill, rock foundation and filter sand-gravel. Considering the seismotectonic features of the dam site, the $M_{w}$ 5.7 Upland California earthquake with a maximum acceleration value of $0.24 \mathrm{~g}$ was utilized in the dynamic analysis. In the static analysis, the maximum settlement value was observed in the middle of the dam body fill and in the crest. The maximum value of settlement was computed at the top of the dam body. According to slope stability analysis; the static slope safety factor is greater than 2.0 which indicates that the slope stability is in balance. In the dynamic case, the value of the safety factor is reduced to the value of 1.3. This result indicates that the slope is in equilibrium whereas the slope stability tends to decline if the earthquake acceleration value increases. In terms of 2D deformations and the state of slope stability under seismic forces; the $M_{w} 5.7$ earthquake with a maximum acceleration value of $2.4 \mathrm{~g}$ will not produce any risk based on the finite element model of the dam used in this study.
\end{abstract}

\section{Keywords}

Aksıfat dam, finite elements method, static and dynamic analysis, slope stability

\footnotetext{
${ }^{*}$ Corresponding Author: Ayse Bengu Sunbul, absunbul@beun.edu.tr
} 


Aksaray University
Journal of Science and Engineering
e-ISSN: 257-1277
http://dergipark.gov.tr/asujse
http://asujse.aksaray.edu.tr

Research Article

\title{
Mersin Aksıfat Barajının Statik ve Dinamik Davranışının İncelenmesi
}

\author{
Ayşe Bengü Sünbül*
}

Bülent Ecevit Üniversitesi, İnşaat Mühendisliği Bölümü, 67100, Zonguldak, Türkiye

\section{Özet}

Bu çalışmada ön yüzü beton kaplı kaya dolgu baraj olan Aksıfat Barajının inşa aşamasında ve su tutma aşamalarındaki oturma davranışı incelenmiştir. Toplam yer değiştirme ve gerilme dağılımları belirlenmesi amacıyla sonlu elemanlara dayalı PLAXIS programı kullanılarak iki boyutlu düzlemsel şekil değiştirme analizleri yapılmıştır. Barajı oluşturan malzemelere ait parametreler, proje kapsamında yapılan araştırma kuyu kesit verilerinde, geoteknik raporlardan ve literatür çalışmalarından elde edilmiştir. Baraj modelinde ana kaya için lineer elastik malzeme modeli; kaya dolgu, kaya temel ve filtre kum-çakıl için Mohr-Coulomb (MC) modelleri tercih edilmiştir. Baraj ile birlikte temel zemininde davranışının modellenmesi için zemin formasyonları da sonlu elemanlar modeline dahil edilmiştir. Statik çözüm için barajın kendi ağırlığı altında oluşan yer değiştirme ve gerilme analizleri yapılmıştır. Barajın yer aldı ğ bölgenin sismotektoniği dikkate alınarak, $0.24 \mathrm{~g}$ maksimum ivme değerine sahip $\mathrm{M}_{\mathrm{w}} 5.7$ Upland Kaliforniya depremi dinamik analizlerde kullanılmıştır. Statik durum analizinde maksimum oturma değeri baraj gövde dolgusunun ortalarında ve krette oluştuğu gözlemlenmiştir. Baraj gövdesi içerisinde hesaplanan maksimum oturma, baraj gövde ortasının en üst noktasında elde edilmiştir. Şev stabilite analizlerine göre; statik durumda elde edilen şev güvenlik katsayısı 2.0 dan büyüktür ve bu durum şevin dengede olduğunu göstermektedir. Dinamik durumda ise elde edilen güvenlik katsayıları değerleri düşerek 1.3 civarında elde edilmiştir. Bu durum şevin dengede olduğunu ancak deprem ivme değerinde artış olması durumunda şev dengesinin bozulma eğiliminde olduğunu göstermektedir. Sismik kuvvetler altında iki boyutta yer değiştirmeler ve şev stabilitesi değerlendirildiğinde inceleme bölgesinde $0.24 \mathrm{~g}$ ivmeli $\mathrm{M}_{\mathrm{w}} 5.7$ büyüklüğünde bir depremin oluşması halinde incelenen barajın sonlu eleman modelinde risk oluşturacak boyutta deformasyonlar meydana gelmesi öngörülmemektedir.

\section{Anahtar Kelimeler:}

Aksıfat barajı, sonlu elemanlar metodu, statik ve dinamik analiz, şev stabilitesi

* Sorumlu Yazar: Ayşe Bengü SÜNBÜL, absunbul@beun.edu.tr 


\section{GíRiş}

Son yüzyılda nüfus artışındaki hız ve buna bağlı ihtiyaçların artması doğal kaynakların daha fazla tüketilmesine sebep olmaktadır. Doğal kaynakların en önemlileri olan yeraltı ve yer üstü su kaynaklarının sürekli ve verimli kullanılması için en çok başvurulan yol baraj imalatıdır [1]. Günümüzde baraj mühendisliğindeki teknolojik gelişmeler ön yüzü beton kaplı kaya dolgu (ÖYBKKD) baraj yapımını yaygınlaştırmıştır. Özellikle geçirimsiz malzemenin yetersiz olduğu bölgelerde bu tür barajlar inşa edilmektedir.

Türkiye de barajların tasarlanması ve yapılması Devlet $\mathrm{Su}$ İşleri Kurumu tarafından gerçekleştirilmektedir [2]. Baraj yerinin topoğrafyası, jeolojisi ve temel şartları, barajın yüksekliği ve dolgusunda kullanılacak malzemeler kadar barajın deprem durumu da göz önünde bulundurulması gereken bir önemli özelliktir [3-4]. Barajların hem gövde dolgu malzemesi hem de gövde biçimleri dikkate alındığında; kaya dolgu barajın evrimi beton yüzlü kaya dolgu baraj ile başlamış, daha sonra ana tipleri geliştirilmiştir [5].

Günümüzde inşa edilen modern ön yüzü beton kaplı kaya dolgu (ÖYBKKD) barajlar dik eğimli ve oldukça yüksek inşa edilebilmektedirler. Barajların güvenliği göz önüne alındığında, özellikle deprem bölgelerinde yer alan barajların tasarım aşamasında dinamik yükler altında nasıl bir davranış biçimi göstereceğinin önceden kestirimi ileride meydana gelebilecek felaketlerin önüne geçecektir. Bu bağlamda, literatürde birçok çalışma yer almaktadır. Zhang ve ark. [6] rijit yay modeli kullanarak barajların temel ve şevlerin statik ve dinamik katsayılarını tespit ederek stabilite analizleri yapmıştır. Kenya Thika Barajı yapımında gözlemlenen yüksek boşluk suyu basıncı ve akabinde gerçekleşen stabilite problemlerini sonlu elemanlar metodu kullanarak incelemiştir [7]. Bayraktar ve ark. [3] farklı rezervuar uzunluğunun barajlardaki sismik performansı nasıl etkilediğini incelemiştir. Lia ve ark. [8] farklı özellikler taşıyan beton yüzlü barajların gerilme alanlarını sonlu elemanlar yöntemi kullanarak incelemiştir. Çalamak ve ark. [9] toprak dolgu barajlarda hazne seviyesindeki ani düşmenin şev stabilitesindeki değişimlerini incelemiştir.

Barajların dinamik davranışı modellenirken barajın gövde ağırlığın, statik su basıncı ve statik yükleme kaynaklı statik etkiler, deprem bölgelerinde inşa edilmiş barajlarda dinamik kuvvetlere ilave bir etki meydana getirir [10]. Baraj rezervuarının dolu veya boş olması; dolu olması durumunda su seviyesinin de ayrıca statik ve dinamik olarak dolgu barajlarında etkisi bilinmektedir, rezervuar su seviyesinin ani ve/veya yavaş düşmesi baraj dolgusunda şev stabilitesi dengesini bozan bir etki yapmaktadır [11]. Bu yüzden barajlarda gerilme 
deformasyon analizlerinde, baraja etki edene statik ve dinamik kuvvetlerin ayr1 ayr1 değerlendirilmesi gerekmektedir [12].

$\mathrm{Bu}$ çalışmada, ÖYBKKD barajda deformasyon analizi ve deprem davranışı etkisi araştırılmaktadır. Analizi yapılan baraj Mersin ili, Erdemli ilçesinde inşaatı devam eden Aksıfat Barajıdır. Barajın inşa amacı çevre yerleşimlerin sulama, içme ve kullanma suyu ve elektrik üretimidir. Ön yüzü beton kaplı olan bu barajın zemininde oluşabilecek deformasyon, dolguda oluşması muhtemel şev hareketi ve öngörülmemiş deformasyonların yapı da meydana getireceği hasarın belirlenmesine yönelik 2 boyutlu sonlu elemanlar analizi yapılmıştır. Şev stabilite analizlerinde Bishop ve Morgenstern-Price yöntemi, statik ve dinamik analizlerde Plaxis 2D V9 Dinamik modül kullanılmıştır. Sismik analizlerde barajın bulunduğu konum da dikkate alınarak 0.24 g maksimum ivme değerine sahip $\mathrm{M}_{\mathrm{w}} 5.7$ Upland Kaliforniya depremi kullanılmıştır.

\section{MALZEME VE YÖNTEM}

\subsection{Sonlu Elemanlar Metodu}

Sonlu Elemanlar (SE) Yöntemi, çeşitli mühendislik problemlerine kabul edilebilir bir yaklaşımla çözüm arayan bir sayısal çözüm yöntemidir. Bilgisayarların gelişimine bağlı olarak kullanım alanları gelişmektedir. Yöntem kısmı diferansiyel denklemlerle ifade edilen problemleri, doğrusal ve doğrusal olmayan problemleri çözmede kullanılmaktadır. Problem sonlu elemanlara ayrılır, her bir eleman için mevcut sınır şartları göz önünde tutularak ortamın matris şeklindeki denklemleri her eleman için belirlenir. Analizi yapılacak her eleman sonlu sayıda parçalara bölünür. Bu parçalar çok sayıda parçalara bölünürse detaylı hesap sonucu çıkar ancak süre uzar, az sayıda parçalara bölünürse hesap kaba sonuçlar verir, ancak hızlı olur. Mevcut sınır şartları dikkate alınarak elemanlar birleştirilir ve tüm ortam için matris biçiminde denklemler elde edilir. Elde edilen denklemler çözülerek bilinmeyenler hesaplanır. Sürekli ortam öncelikle sonlu sayıda elemanlara bölünür ve sonlu sayıdaki bu düğüm noktalarında hesaplamalar yapilır [13-14].

\subsection{Aksıfat Barajının Sonlu Elemanlar Modeli}

Mersin ili Silifke ve Erdemli ilçelerine bağlı 82.140 dekar alanın sulamasını sağlayacak ve yılda $8.10 \mathrm{Gwh} / \mathrm{y} 1$ enerji üretecek olan Aksıfat Barajı inşaatı devam etmekte olup, sözleşmeye göre 2018 yılında tamamlanması planlanmaktadır. Baraj temelden $83.0 \mathrm{~m}$ yüksekliğinde, kret genişliği $49.0 \mathrm{~m}$, önyüzü beton kaplı kaya dolgu tipinde $1.553 .000 \mathrm{~m}^{3}$ gövde hacmine sahip 
olacak şekilde planlanmıştır. Şekil 1'de barajın konumu ve Şekil 2'de baraj gövde tipi kesiti ve zon özellikleri verilmiştir.

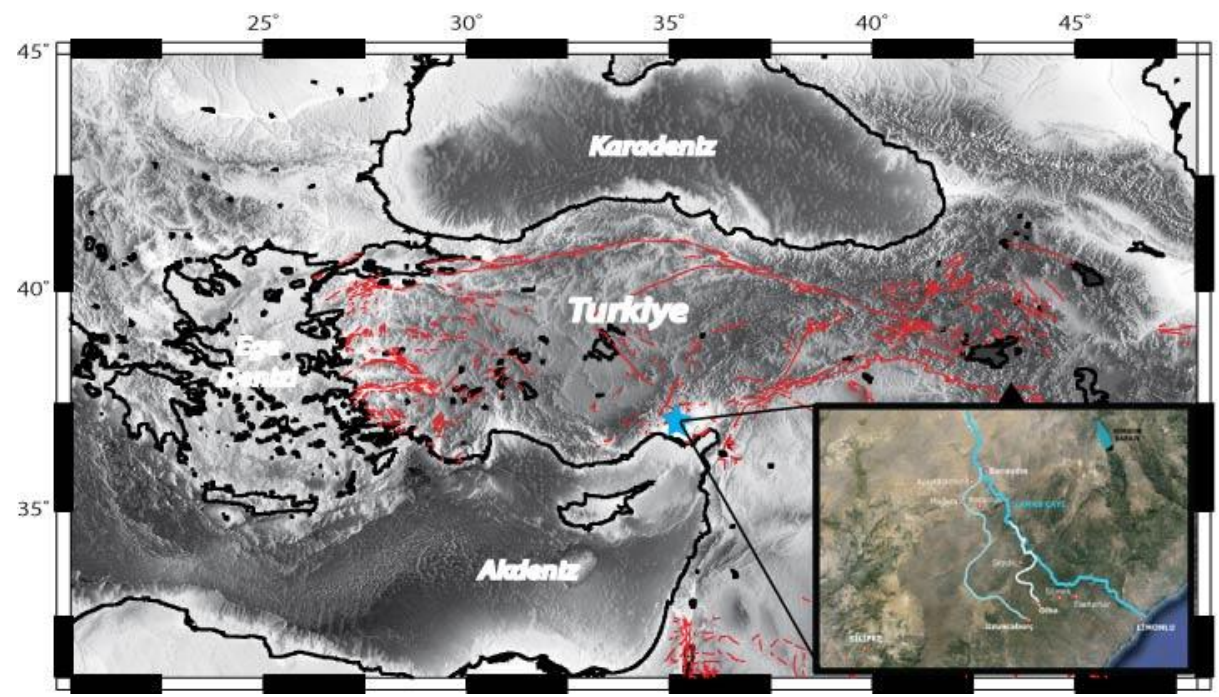

Şekil 1. Aksıfat barajının inşa edildiği yerin uydu görüntüsü.

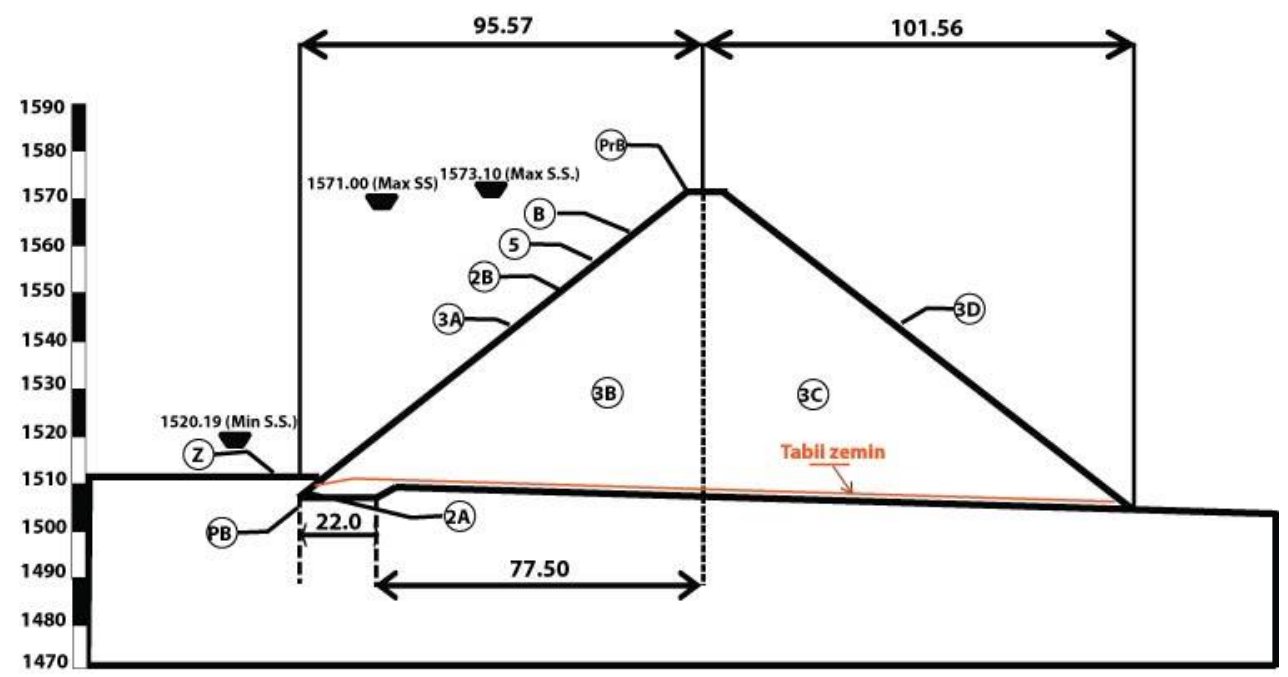

Şekil 2. Aksıfat barajının gövde tipi kesiti ve zon özellikleri.

Bölgenin genel jeolojisiyle ilgili yapılan araştırmalarda; bölgenin genelinde Miyosen çökelleri yayılım göstermektedir. Erdemli ilçesinin kuzeyindeki Mesozoyik-Senozoyik, Silifkenin batısındaki Paleozoyik, Mesozoyik ve Senozoyik yaşlı kayaçlar basenin çıkıntılarına rastlanmaktadır. Aynı çalışmada Miyosen çökeller diskordanla otururken, Pliyosen çökeller de Miyosen üzerine uyumsuzluk ile gelir, ayrıca Pliyoseni örten alüvyonlar stratigrafik istifi tamamlamaktadır. Bölgede yaşlıdan gence doğru Üst Kretase yaşlı ofiyolit, Miyosen yaşlı Karaisalı kireçtaşı ile kiltaşı, silttaşı-kumtaşı, konglomera-killi kireçtaşı ardalanması ile temsil edilen Köselerli formasyonu ve Kuvaterner yaşlı alüvyonlar ile temsil olunur. Oldukça geniş alanlarda yüzeylenen kireçtaşları sarımsı, beyaz renkli ve karstik boşlukludur. Karstik kireç 
taşlar üzerine sırasıyla konglomera, traverten, kil, alüvyon ve yamaç molozu gibi güncel çökeller gelmiştir [15].

Sonlu elemanlar analizleri için, arazide uygulanan DSİye ait sondaj logları incelenmiş ve baraj gövdesinin oturacağı düşünülen alana ait 11 adet sondajdan $40 \mathrm{~m}$ derinlikli düşey temel sondaj1 karakteristik zemin profili oluşturmak amacıyla seçilmiştir (Tablo 1).

Tablo 1. Karakteristik zemin profilini yansitan sondaj logu.

\begin{tabular}{|c|c|}
\hline $\begin{array}{c}\text { Tabaka } \\
\text { Kalınlığı (m) }\end{array}$ & Temel Sondaj Kuyusu \\
\hline $0-4.5$ & Gri renkli çatlaklı kumtaşı \\
\hline $4.50-5.0$ & Gri renkli sert, killi kireçtaşı. \\
\hline $5.0-5.90$ & Gri renkli sert, kapalı çatlaklı, çatlakları kalsit dolgulu kumtaşı. \\
\hline $5.90-10-20$ & Gri renkli sert, killi kireçtaşı. \\
\hline $10.20-12.0$ & $\begin{array}{l}\text { Kırmızımsı renkli, dane çapı } 0,2-3 \mathrm{~cm} \text { arasında değişen yarı köşeli ve yuvarlaklaşmış ofiyolit, } \\
\text { radyolarit, çakıllı kalsit dolgulu konglomera. }\end{array}$ \\
\hline $12.0-12.80$ & $\begin{array}{l}\text { Gri renkli içerisinde } 0,2-0,6 \mathrm{~cm} \text { çaplı yuvarlaklaşmıs, ofiyolitradyolarit çakıllı kum çimentolu } \\
\text { konglomera. }\end{array}$ \\
\hline $12.80-14.25$ & Haki renkli orta sert, kiltaşı-kumtaşı. \\
\hline $14.25-14.75$ & Gri renkli sert, kumlu kireçtaşı. \\
\hline $14.75-20.40$ & Gri renkli sert, killi kireçtaş1. \\
\hline $20.40-21.90$ & Gri renkli sert, içerisinde tane çapı $0,6-2 \mathrm{~cm}$ ofiyolitradyolarit çakıllı karbonat çimentolu konglomera. \\
\hline $21.90-40.00$ & Siyah renkli yumuşak, kumtaşı silttaşı (kömür). \\
\hline
\end{tabular}

Baraj temel malzemesi ana kaya-sağlam kaya olarak kabul edilmiş ve buna uygun geoteknik parametreler SK4'e uygun atanarak, Tablo 2'de verilen diğer baraj dolgu malzemeleriyle beraber modele yansitılmıştır.

Tablo 2. İmalatta kullanılan malzemelerin karakteristik özellikleri; Maksimum Dane Boyutu ( $\left.\mathrm{D}_{\max }, \mathrm{mm}\right)$, Tabaka Kalınlığı $(\mathrm{L}, \mathrm{cm})$, Kuru Birim Hacim Ağırlık $\left(\gamma_{\mathbf{k u r u}}, \mathbf{k N} / \mathbf{m}^{3}\right)$, Doygun Birim Hacim Ağırlık $\left(\gamma_{\mathbf{d o g u n}}\right.$, $\left.\mathbf{k N} / \mathbf{m}^{3}\right)$, Elastisite Modülü $\left(\mathbf{E}, \mathbf{M N} / \mathbf{m}^{2}\right)$, Poisson Oranı (v, birimsiz), İçsel Sürtünme Açısı $\left(\boldsymbol{\Phi},{ }^{\circ}\right)$, Kohezyon (c, kN/m²), Geçirimlilik Katsayısı (kx $\mathbf{m} / \mathbf{g u ̈ n})$, Geçirimlilik Katsayısı (ky, m/gün).

\begin{tabular}{llcccccccccc}
\hline Zon & \multicolumn{1}{c}{ Cinsi } & $\mathbf{D}_{\mathbf{m a x}}$ & $\mathbf{L}$ & $\boldsymbol{\gamma}_{\mathbf{k u r u}}$ & $\boldsymbol{\gamma}_{\text {doggun }}$ & $\mathbf{E}$ & $\mathbf{v}$ & $\mathbf{\Phi}$ & $\mathbf{c}$ & $\mathbf{k}_{\mathbf{x}}$ & $\mathbf{k}_{\mathbf{y}}$ \\
\hline 2A & Çevresel Derz Filtre Zonu & 3.8 & 20 & 16 & 18 & 150 & 0.28 & 38 & 50 & 1 & 1 \\
2B & Elenmiş Kaya veya Alüvyon & 7.6 & 40 & 18 & 20 & 65 & 0.33 & 38 & 50 & 0.25 & 0.25 \\
3A & Seçilmiş Kaya Geçiş Zonu & 30 & 40 & 20 & 23 & 80 & 0.3 & 42 & 50 & 1 & 1 \\
3B & Ocak Kayası ile Dolgu & 60 & 90 & 21 & 24 & 90 & 0.3 & 42 & 50 & 1 & 1 \\
3C & Ocak Kayası ile Dolgu & 80 & 100 & 20 & 23 & 90 & 0.3 & 43 & 50 & 1 & 1 \\
3D & Ocak Kayası ile Dolgu & 100 & - & 22 & 23.5 & 90 & 0.3 & 43 & 50 & 1 & 1 \\
5 & Yerinde Dökme Beton & 75 & 40 & 23,5 & - & 110 & 0.3 & 9 & 387 & - & - \\
B & Önyüz Beton Kaplama & 30 & - & 23,5 & - & 70 & 0.2 & 9 & 387 & - & - \\
PB & Topuk Plağ1 Betonu & $40-60$ & - & 23,5 & - & 90 & 0.2 & 9 & 387 & - & - \\
PrB & Parapet Betonu & - & - & 23,5 & - & 90 & 0.2 & 9 & 387 & - & - \\
Anakaya & Sağlam kaya & - & - & 17 & - & 150 & 0.28 & 10 & 100 & - & - \\
\hline
\end{tabular}


Mersin ili ve çevresinin depremselliği incelendiğinde, çalışma bölgesi Doğu Anadolu Fay zonu ve Kıbrıs ada yayı arasında; Afrika ve Anadolu plakasının sınır bölgesinde yer almaktadır [16]. Türkiye deprem bölgeleri haritasında; Mersin ili 4 farklı deprem bölgesini içermektedir. Ancak baraj yeri incelendiğinde, Erdemir bölgesi 4. derece deprem bölgesinde ve 3. derece bölge sınırına yakın bir kısımda yer almaktadır. Sismik risk çalışmalardan elde edilen verilere göre, baraj yeri ve yakın çevresinde gözlenebilecek maksimum ivme değeri 0.25 g mertebesindedir [17-18] (Şekil 3).

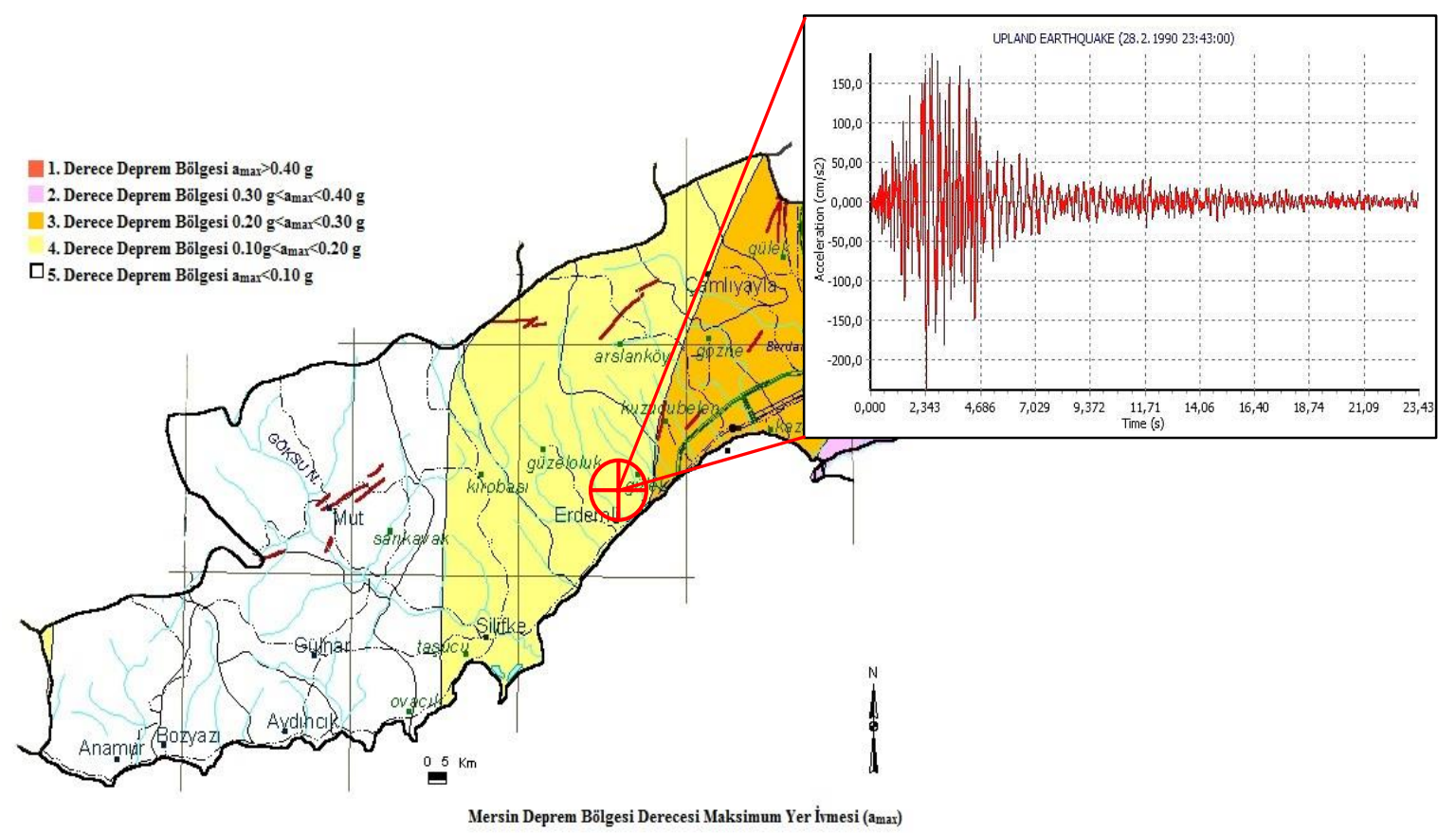

Şekil 3. Barajın depremsellik durumu [17] ve dinamik analizlerde kullanılan $\mathrm{M}_{\mathrm{w}}: 5.4$ deprem ivme kaydı [19].

Baraj bölgesinin bulunduğu konum dikkate alındığında, dinamik analizlerde maksimum ivme değerine yakın, 0.24 g ivme değerine sahip $1990 \mathrm{M}_{\mathrm{w}} 5.7$ Upland Kaliforniya depremi ivme kaydının 12 sn'lik kısmında maksimum ivme değerleri aralığı kullanılmıştır [19]. Barajların dinamik analizlerinde; bir barajın bulunduğu konumda meydana gelebilecek maksimum genliğe sahip bir depremin etkisi kullanılır [20]. Bu bağlamda, seçilmiş deprem kaydının bu bölgede olması muhtemel depremde oluşabilecek maksimum ivme spektrum aralığındadır.

\section{SONLU ELEMAN ANALIZLLEII}

\subsection{Yer Değiştirme Analizi}

Aksıfat barajı; sonlu elamanları analizi için Plaxis V9 Dinamik modülde; iki boyutlu düzlem birim deformasyon koşullarının geçerli olduğu kabulü ile analiz edilmiştir. Sonlu elemanlar model analizinde statik ve dinamik durum davranışını matematiksel gerçeğe en yakın biçimde modelleyebilmek için baraj için verilen malzeme ve geometri özellikleri modele yansıtılmıştır. 
Baraj modeli düzlem deformasyon olarak 15 düğüm noktalı üçgensel sonlu elemanlar ile modellenmiştir. Sonlu elaman ağ sıkılığı orta sıkılıkta alınmıştır. Modelin sınır şartlarının ve başlangıç koşullarının en doğru yansıtıldığı sonlu elemanlar ağı belirlenmiş ve 15667 düğüm noktası ve 1881 eleman tanımlanmıştır (Şekil 4).

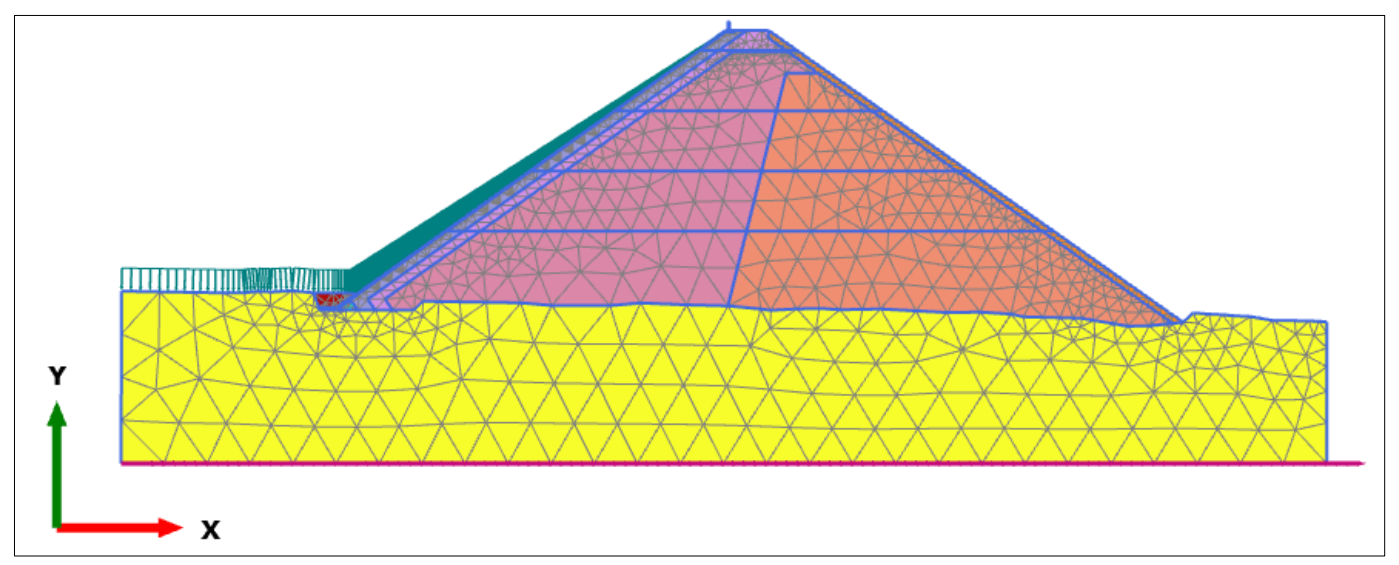

Şekil 4. Analizde kullanılan barajın sonlu elemanlar ağı

Daha önce sunulan Tablo 1'de verilen baraj zonundaki malzemelere uygun ve barajı en yakın şekilde yansıtacak malzeme parametreleri DSİden alınan geoteknik raporlar, jeolojik etütlerden elde edilmiştir. Sunulan tüm bu malzemelerin karakteristik özellikleri, literatürde geçen değerler ile kontrol edilerek kullanılmıştır. Anakaya için lineer elastik malzeme modeli, diğer baraj dolgu ve filtre malzemeleri için Mohr Coulomb malzeme modeli seçilmiştir. Baraj ile birlikte temel zemininin de davranışını gerçekçi bir biçimde modelleyebilmek için barajın altındaki zemin formasyonu da sonlu eleman modeline dahil edilmiştir. Analizde dolgu imalatı, tabakalı olarak sıkıştırılması modele yansıtılmış ve analiz kademeler halinde yapılmıştır. Dolgu imalatında kullanılan tabaka kalınlığı 5 m seçilmiştir. Baraj 5 kademeli analiz edilirken; tabaka kalınlığına bağlı 8 aşamada model analizi tamamlanmıştır. Analizin tek bir kademede yapılması halinde gerçek dışı oturma değerleri elde edilmektedir, bu yüzden çalışmada gerçek tabakalı imalat kademeler halinde hesaplara yansıtılmıştır. Bu durumda sonlu elemanlar modelinde daha gerçekçi deformasyon değerleri elde edilmesi planlanmıştır. Maksimum oturma değeri baraj gövde dolgusunun ortalarında, tek bir kademede modellendiğinde maksimum oturma değerinin krette oluştuğu gözlenmiştir.

Barajlarda stabilite kontrolü yapılırken en önemli parametre boşluk suyu basıncıdır. Bunun için statik analiz durumunda barajda yeraltı su seviyesi mansapta sabit tutularak, ağırlık yüklemesi altında boşluk suyu basınçları hesaplanmıştır. Programın analiz yapabilmesi için barajda suyun ilerleyeceği yolun tahmini olarak çizilmesi gerekmektedir. Şekil 5'de suyun dolgudan geçerken izleyeceği yol, tahmini olarak gösterilmiştir. 


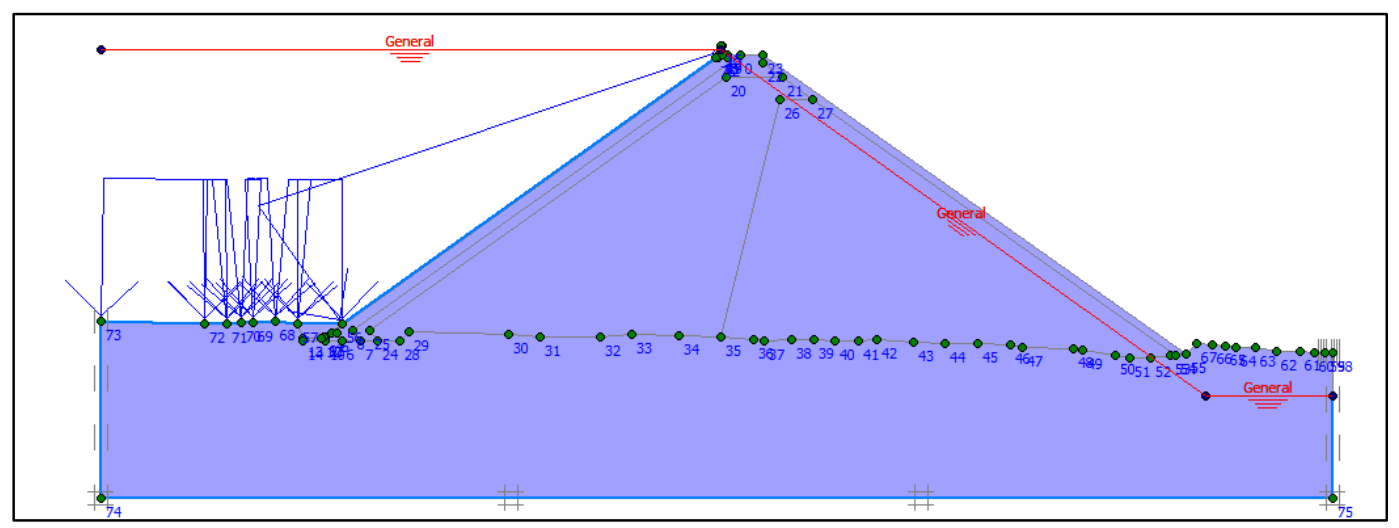

Şekil 5. Barajın dolu hali ve modellemede kullanılan suyun geçiş yolu.

Rezervuar su dolu iken yapılan analiz sonucu incelendiğinde, baraj memba tarafında beliren düşey oturmalar barajın üst kotunda elde edilmiştir. Barajın mansap kısmı üst kotlarında ise, ters yönde kabarma davranışı gözlenmektedir. Analiz sonucunda barajda elde edilen maksimum boşluk suyu basıncı $673.7 \mathrm{kN} / \mathrm{m}^{2}$, minimum boşluk suyu basıncı ise $-150.9 \mathrm{kN} / \mathrm{m}^{2}$ dur. Chrzanowski ve Massiéra [21] baraj imalatının tamamlanmasıyla baraj gövdesi ve kret noktalarındaki deformasyonların barajın su tutmaya başlamasıyla artış gözlenmesinin normal olduğunu belirtmişlerdir. Bu çalışmada, yüksek deformasyonun zaman içinde sönümlenmesi ve dengeye ulaşması beklenmektedir. Dinamik etkiler ve su seviyesindeki değişim bu durumu değiştiren parametrelerdir. Aksıfat barajı için yapılan statik durum analizinde rezervuar dolum sonrası hesaplanan maksimum düşey yer değiştirme $7.92 \mathrm{~cm}$, krette gözlenen oturma ise yaklaşık $8.0 \mathrm{~cm}$ 'dir.

Uluslararası büyük barajlar komisyonu yönetmeliğine göre; "kaya dolgu barajlarda kret oturma miktarı baraj yüksekliğinin \%0.1 ile \%0.2 arasında değerlerde değişebilir” kabulüne göre hesaplanan deformasyon miktarı, Aksıfat Barajı için güvenli tarafta kalmaktadır [1]. Aynı zamanda Chrzanowski ve Massiéra [21] baraj dolgularında hareketliliğin ilk yıllarda fazla olması baraj rezervuarında tutulmaya başlayan suyun baraj kreti üzerinde oluşturduğu etki ve barajın kendi ağırlığı altında yapmış olduğu oturmalardan kaynaklandığını belirttikleri çalışmalarına göre de Aksıfat barajı analizlerinden elde edilen oturma değerleri kabul edilebilir düzeydedir.

Dinamik analizlerde baraj gövdesinde oluşan gerilme dağılımlarını analiz edebilmek için, gövdede üç adet gözlem noktası oluşturulmuştur. Bunlar sırasıyla, barajın üst noktası (A), barajın orta noktası (B) ve barajın alt noktasını (C) temsil etmektedirler. Analizlerin grafiksel gösterimlerinde tanımlanan üç nokta, Şekil 6 ve 7'de sırasıyla düşey yer değiştirme-zaman ve yatay yer değiştirme-zaman değişim grafikleri olarak tanımlanmıştır. Dinamik analiz sırasında 
baraj tabanından etki ettirilen dinamik kuvvetler sonucunda elde edilen yatay yer değiştirmeler değerlendirildiğinde; yatay yöndeki yer değiştirmeler düşey yöndeki yer değiştirmelerden daha büyük çıkmıştır. Buna sebep, bu tür inşa edilen barajlarda kret bölgesinin diğerlerine göre daha ağır tasarlanması mansap ve memba şev eğiminin daha büyük açılarla projelendirmesi olarak söylenebilir. Aksıfat barajı için yapılan dinamik durum analizinde rezervuar dolum sonrası hesaplanan maksimum düşey yer değiştirme $79.2 \mathrm{~cm}$, krette gözlenen oturma ise yaklaşık 80 cm'dir. Baraj imalatı süresince her tabaka imalatından sonra oluşan oturma değerleri ihmal edilerek son durum yatay yer değiştirme değeri ise $12.89 \mathrm{~cm}$ 'dir (Şekil 6).

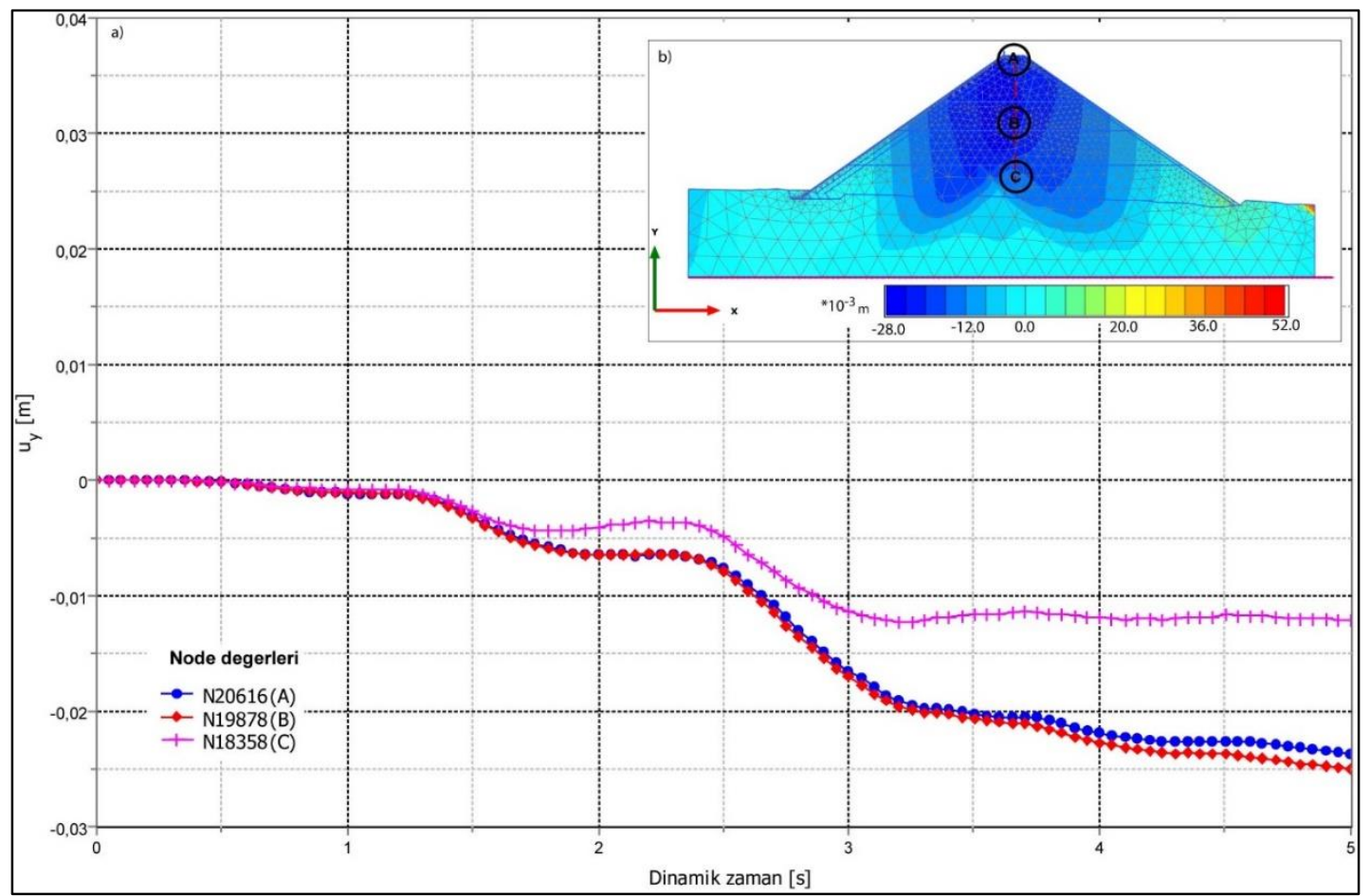

Şekil 6. Analiz sonucunda barajda oluşan düşey yer değiştirme $\left(u_{y}\right)$.

Baraj gövdesinde analiz sonunda gerçekleşmesi beklenen toplam yer değiştirme $127 \mathrm{~cm}$, her fazdaki artımlı (kademeli) yer değiştirme ise $38.08 \mathrm{~cm}$ olarak elde edilmiştir. Bu durumda baraj gövdesi içerisinde hesaplanan maksimum oturma baraj gövde ortasında en üst noktasında elde edilmiştir (Şekil 7). Çalışmadan elde edilen sonuç; Özkuzukıran [22] tarafından aynı özelliklere sahip Karadeniz bölgesi Kurtun barajı için yapılan analizler ile uyumlu sonuçlar vermiştir.

Maksimum yer değiştirmelerin olduğu bölgelerde gerilme dağılımları değerlendirildiğinde, deprem sirasında ve sonrasinda maksimum normal gerilmeler kırılma olması muhtemel bölgeleri, maksimum kayma gerilmeleri ise baraj malzemesinin çökmesi muhtemel alanlarında elde edilmiştir. 


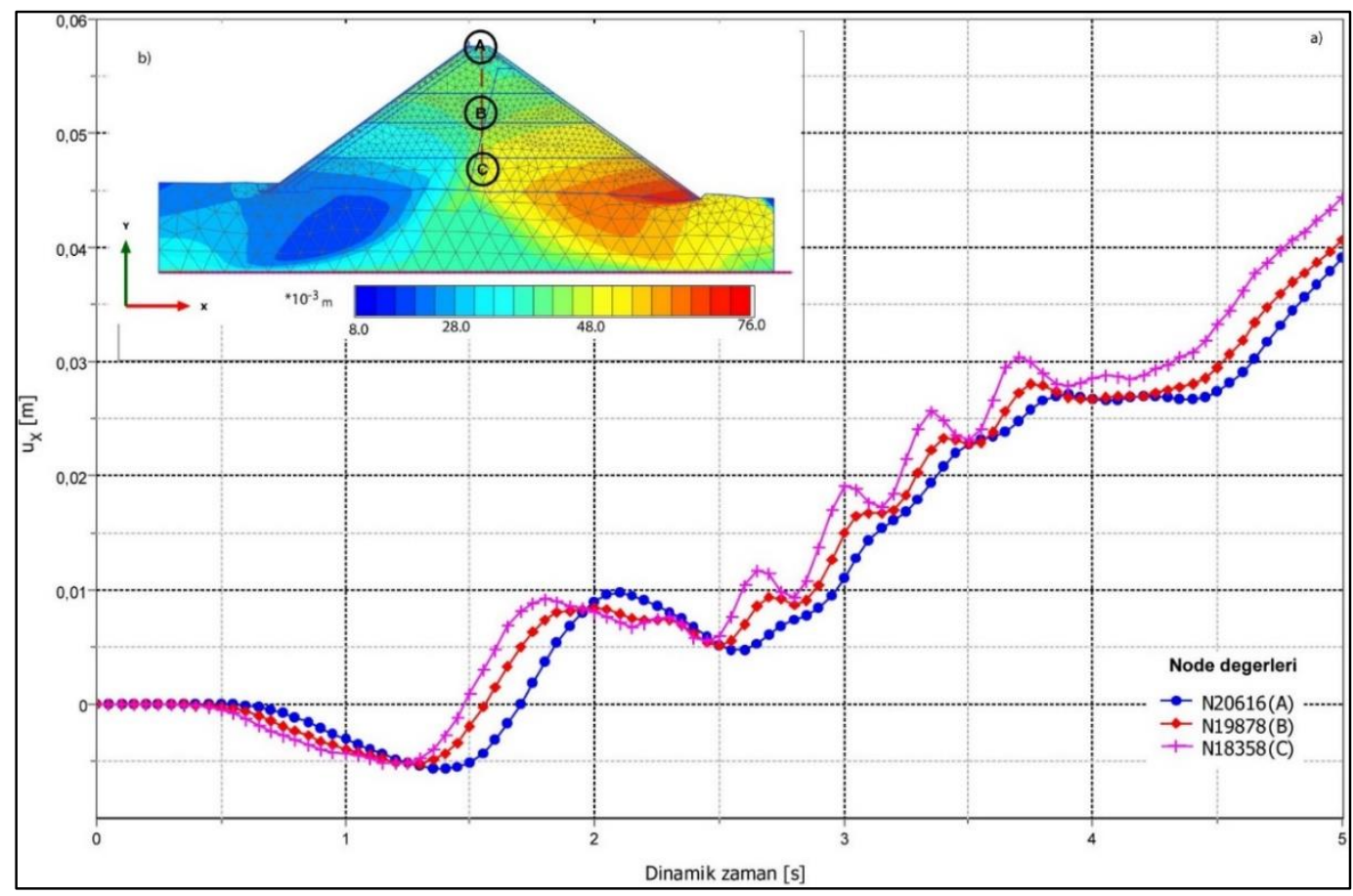

Şekil 7. Analiz sonucunda barajda oluşan yatay yer değiştirme $\left(u_{x}\right)$.

Şekil 8'de barajın iki noktasında dinamik analizlerde elde edilen ivme zaman grafiğinde barajın en üst noktası olan A noktasında en büyük ivme değeri 0.26 g'dir. Sonuç olarak; dinamik analizlerde kullanılan depremin hem yatay hem düşey doğrultu da baraj temelinde ve baraj gövdesinde etkili olması beklenen $0.24 \mathrm{~g}$ yatay sismik yükün baraj güvenliği açısından risk oluşturacak boyutta deformasyona neden olmayacağı öngörülmektedir.

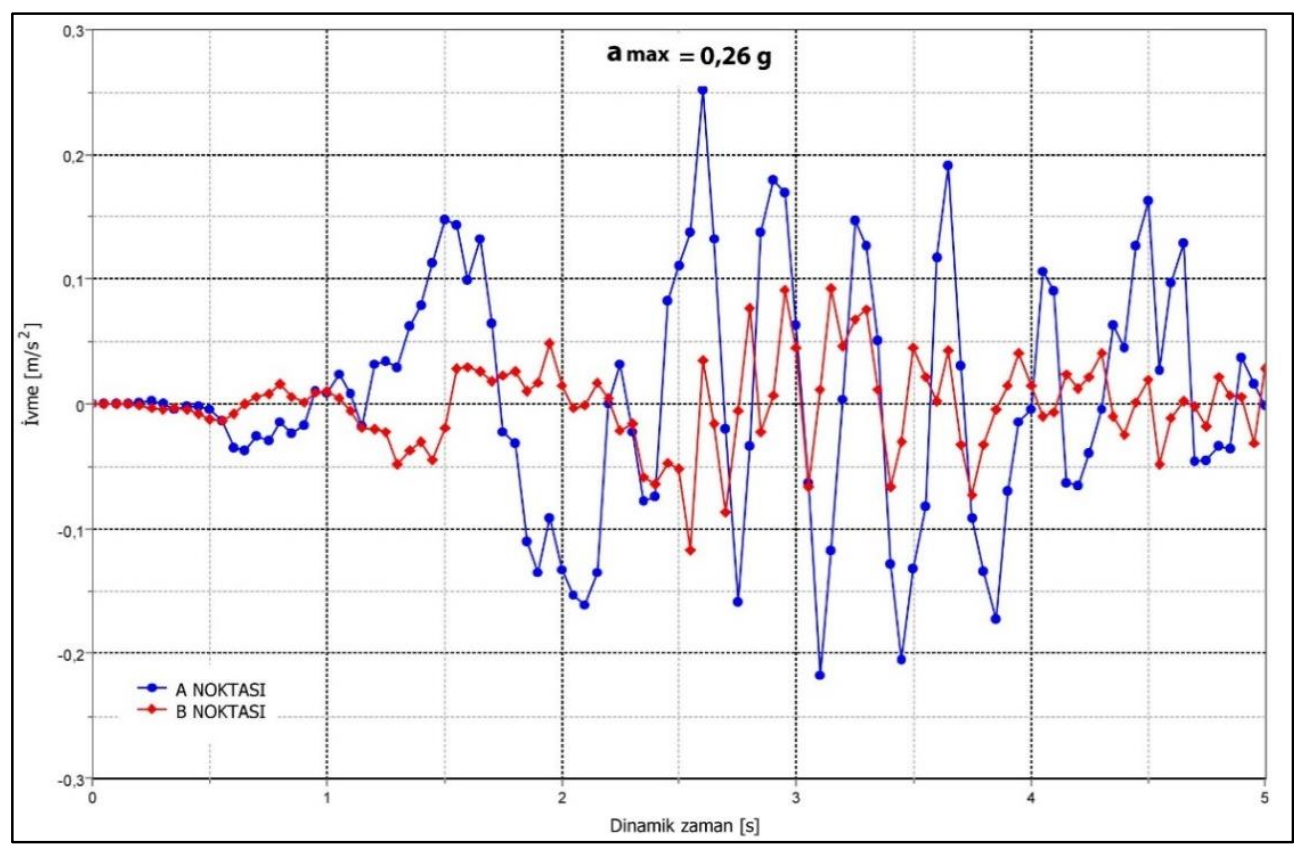

Şekil 8. Analiz sonucunda barajın A ve B noktalarında oluşan maksimum ivme değeri. 


\section{2 Şev Stabilitesi}

Şevlerin deprem veya farklı dinamik yüklemeler altında stabilitesinin araştırılması genellikle limit denge analizleri ile gerçekleşir. Bu analizlerde, kayan zemin kütlesinin yer çekimi ve boşluk suyu etkileri altında oluşan denge durumu araştırılır. İncelenen zemin yapısında, yapının göçmeye karşı yeteri kadar güvenlikte tasarlanmış olması gerekmektedir. Zemin yapısının güvenliği emniyet faktörü parametresi ile tanımlanır [23]. Emniyet faktörü $\left(F_{s}\right)$, mühendislik açısından tanımı kaymaya karşı tutucu kuvvetlerin, kaymaya neden olan kuvvetlere oranı olarak ifade edilir. Buna göre; $F_{s}<1$ ise şev dengesizdir, $F_{s}=1$ ise şev limit denge durumundadır ve $\mathrm{F}_{\mathrm{S}}>1$ ise şev dengededir. Bir şevin efektif gerilmeler altındaki davranışı analizlerinde, kayma yüzeyi boyunca efektif gerilmelerin hesaplanmasına ihtiyaç duyulur. Bu hedef doğrultusunda kayan kütle modellemelerde, dik olarak dilimlere ayrılır. Kayma yüzeyi eğri bir şekle sahip olduğundan ve şev boyunca zemin fiziksel özellikleri ve boşluk suyu basıncı değişebildiğinden, kayan zeminin dilimlere ayrılması ile göreceli olarak homojen bir modelleme alanı elde edilir. Dairesel bir kayma dairesi üzerinde her bir dilime etkiyen dilim ağırlığı (W), dilim taban normal $(\mathrm{N})$ ve kesme $(\mathrm{S})$ kuvvetleri ve dilimler arasi normal $\left(\mathrm{E}_{\mathrm{L}}, \mathrm{E}_{\mathrm{R}}\right)$ ve kesme $\left(\mathrm{X}_{\mathrm{L}}, \mathrm{X}_{\mathrm{R}}\right)$ kuvvetleri belirlenerek modelleme yapılır (Şekil 9).

$\mathbf{W}$ : b genisliginde ve $\mathrm{h}$ yuksekligindeki dilimin toplam agirligi $\mathbf{N}$ : dilim tabanindaki toplam normal kuvvet

Sm : dilim tabaninda olusan kayma kuvveti

$E_{L}, E_{R}$ : dilimin solunda ve saginda olusan dilimler arasi normal kuvvet $\mathbf{X}_{\mathbf{L}}, \mathbf{X}_{\mathbf{R}}$ : dilimin solunda ve saginda olusan dilimler arasi kesme kuvveti D : cizgisel dis yuk

kW : dilim merkezinden etkiyen sismik yuk

$\mathbf{A}_{\mathbf{L}}, \mathbf{A}_{\mathbf{R}}$ : dilimin solundan ve sagindan etkiyen yeralti suyu kuvveti

$\mathbf{R}$ : dilim uzerinde olusan kuvvetlerin hesaplamasinda kullanilan yaricap

$\boldsymbol{\alpha}$ : dilim taban orta noktasina cizilen tegetin yatayla yaptigi aci

$\mathbf{d}, \mathbf{x}, \mathbf{a}$ : geometrik uzunluklar ve moment kollari

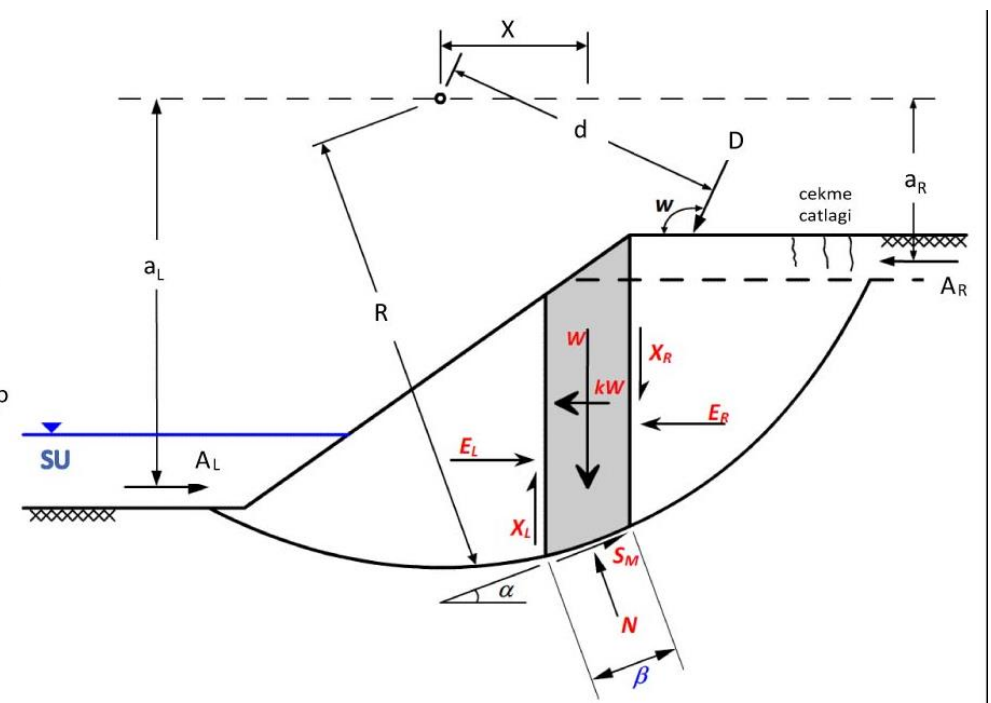

Şekil 9. Şev stabilite metodunda kullanılan dilim yöntemi [24].

Limit denge durumu sağlanması için dilim tabanında mobilize olması gereken kayma mukavemeti denklem (1) ile bulunur; Bağıntıda verilen $F$ güvenlik sayısını ve $\beta$ ise dilim tabanının genişliğini temsil etmektedir.

$S_{m}=\frac{s \beta}{F}=\frac{\beta\left(c^{\prime}+\left(\sigma_{n}-u\right) \tan \phi^{\prime}\right)}{F}$ 
Şekil 1'de gösterilen sistemin hesaplanması halinde kayma dairesinin emniyet sayısı elde edilir. Emniyet sayısı en genel haliyle moment $\left(\mathrm{FS}_{\mathrm{m}}\right)$ ve kuvvet $\left(\mathrm{FS}_{\mathrm{k}}\right)$ dengeleri için sırasıyla denklem

(2) ve denklem (3) yardımıyla hesaplanır.

$$
\begin{aligned}
& F S_{m}=\frac{\sum\left(c^{\prime} \beta R+(N-u \beta) R \tan \phi^{\prime}\right)}{\sum W x-\sum N f \pm \sum D d} \\
& F S_{k}=\frac{\sum\left(c^{\prime} \beta \cos a+(N-u \beta) \tan \phi^{\prime} \cos a\right)}{\sum N \sin a-\sum D \cos \omega}
\end{aligned}
$$

Yukarıdaki denklemlerde c', efektif kohezyon, $\varphi^{\prime}$ efektif içsel sürtünme açısı, N, dilim tabanındaki normal kuvvet, $\mathrm{W}$, dilim ağırlığı, $\alpha$, dilim alt yüzeyinin eğimi, $\mathrm{u}$, boşluk suyu basıncı, D, noktasal yük, $\beta, \mathrm{R}, \mathrm{x}, \mathrm{f}, \mathrm{d}$ ve $\omega$ ise geometrik değişkenlerdir. Dilim yöntemi kullanılarak yapılan şev stabilitesi analizlerinde genellikle sadece moment dengesi ya da moment ve kuvvet dengesi hesaplanarak modelleme yapılır. Bishop [24] yönteminde denge koşullarından denge ve moment dengesini sağlamakta, yatay denge şartı gözetilmemektedir. Morgenstern-Price [25] yöntemi tüm denge denklemlerini sağlar ve dilimler arası normal ve kesme kuvvetleri arasındaki oran da dilimin geometrik konumuna göre değiştirilebilir. $\mathrm{Bu}$ çalışmada her iki yöntemde kullanılarak denge koşulları araştırılmıştır.

\subsection{1 Şev stabilitesi analizi}

Aksıfat barajında oluşabilecek şev yenilmeleri, Mohr-Coulomb malzeme modeli ile, Bishop [24] ve Morgenstern-Price [25] yöntemleri kullanılarak analiz edilmiştir. Analizler barajın statik halinde ve $0.24 \mathrm{~g}$ deprem ivmesi etkimiş halde olmak üzere iki durum için yapılmıştır (Şekil 10). Memba tarafında tahmini kayma yüzeyleri barajın kretinde ve baraj topuk plağının olduğu kısım olarak seçilmiştir. Barajın statik durum çözümünde Bishop yöntemi ile elde edilen minimum moment güvenlik katsayısı 2.23'dir. Morgenstern-Price yöntemi ile statik durumda elde edilen minimum moment güvenlik katsayısı 2.22 ve minimum kuvvet güvenlik katsayısı 2.21'tür.

Yatayda 0.24 g'lık bir deprem ivmesinin etkilemesi ile oluşan dinamik durumdaki analizde statik durumda elde edilene göre daha düşük güvenlik katsayıları elde edilmiştir. Dinamik durumda Bishop çözümü ile elde edilen minimum moment güvenlik katsayısı 1.30'dir. Morgenstern-Price yöntemi ile elde edilen dinamik durum minimum moment güvenlik katsayıs1 1.310, kuvvet güvenlik katsayısı ise 1.309 'dur. Duyarlılık analizleri sonucunda statik durumdaki güvenlik katsayıları dinamik durumda elde edilen güvenlik katsayılarından büyüktür. Sonuç olarak; programa girilen $0.24 \mathrm{~g}$ kadarlık yatay sismik yük şevin stabilitesi açısından risk oluşturacak boyutta barajda deformasyona neden olmadığı görülmüştür. 


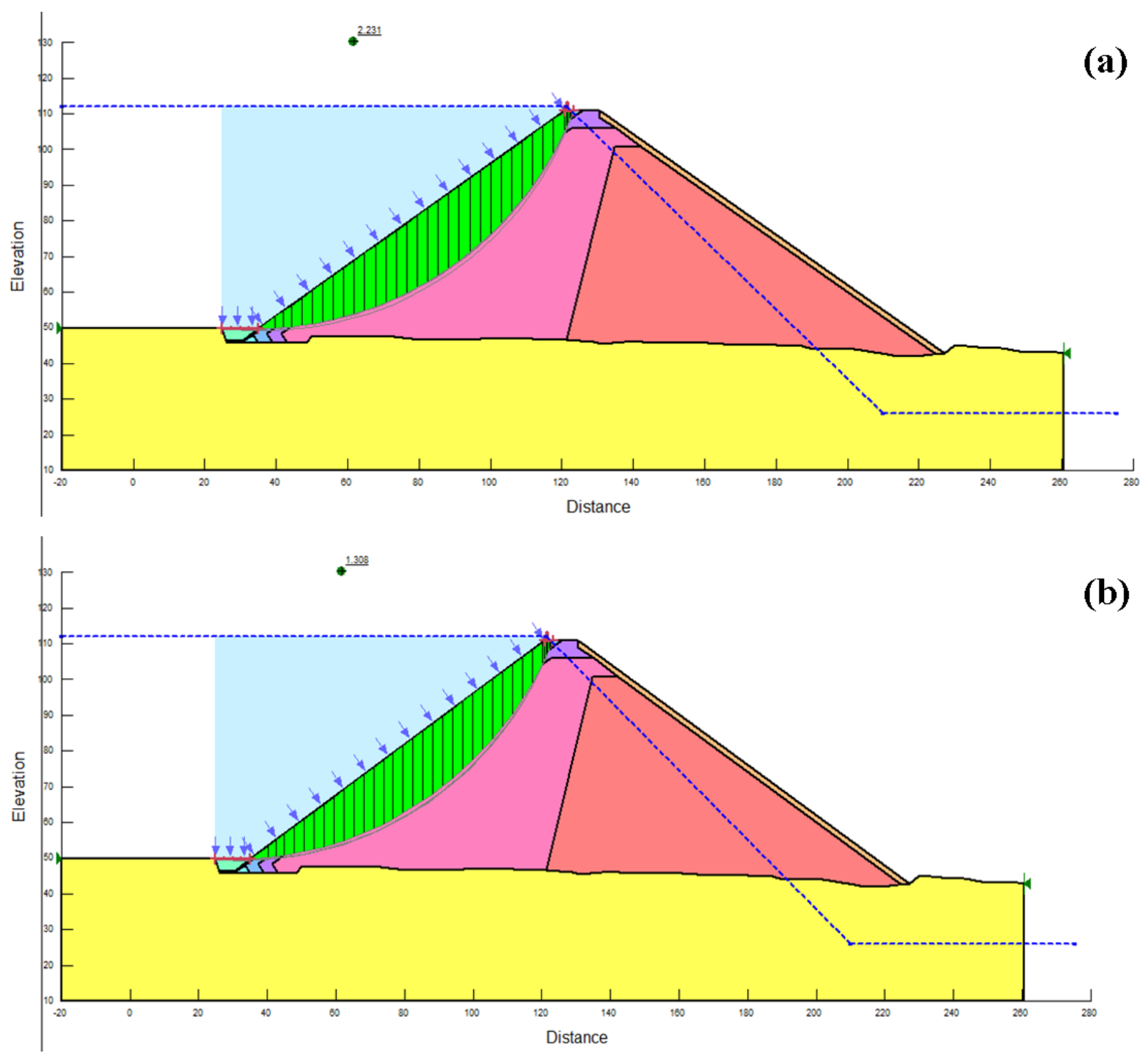

Şekil 10. En kritik kayma dairesi ve dilimler; a) Statik durum ve b) Dinamik durum.

\section{DEĞERLENDİRME}

Baraj, statik durumda iki boyutta yer değiştirme değerleri hesaplanarak ayrıca şev duyarlılığ analizi yapılarak değerlendirilmiştir. Statik durum analizinde baraj gövdesinde meydana gelen yer değiştirmeler incelendiğinde, barajın temelinden kret bölgesine doğru artış gösterdiği görülmüştür. Bu durumda maksimum yer değiştirme krete en yakın bölgede elde edilmiştir.

Sonlu eleman modelinin gerilme deformasyonları $0.24 \mathrm{~g}$ maksimum ivme değerine sahip $\mathrm{M}_{\mathrm{w}}$ 5.7 Upland Kaliforniya depremi ivme kayıtları altında analiz edilmiştir. Bu analizlerde barajda elde edilen yer değiştirme ve gerilme değerleri düşük çıkmıştır. Bu bağlamda hesaplara katılan deprem kuvveti etkisi risk oluşturan etki göstermemiştir. Baraj ve zeminin bir arada modellenmesi sonucu baraj gövdesinin memba ve mansap şev eğimleri üzerinde talveg kotuna yakın yerlerde belirlenmiştir. 
Bishop [24] ve Morgenstern-Price [25] yöntemlerinden her ikisi için; statik durumda şev stabilite güvenlik katsayıları birbirine yakın elde edilmiştir. Statik durumda her iki yöntemde elde edilen şev güvenlik katsayısı 2.0'dan büyüktür ve bu durum şevin dengede olduğunu göstermektedir. Dinamik durumda ise her iki yöntemden elde edilen güvenlik katsayıları değerleri düşerek 1.3 civarında olarak belirlenmiştir. Bu durum şevin dengede olduğunu ancak ivme değerinde artış olması durumunda şev dengesinin bozulma eğiliminde olduğunu göstermektedir. Dinamik durumdaki analizlerde kullanılan $0.24 \mathrm{~g}$ büyüklüğündeki sismik yük bu haliyle baraj güvenliği açısından risk oluşturmamaktadır. Dinamik analizlerde bölgenin depremselliği göz önünde tutularak geçerli ivmelerin en az \%50 artırılarak analizlerde kullanılması önerilebilir.

Sonuç olarak; deprem bölgelerinde inşa edilecek barajlarda sadece statik hesaplarla inşa edilecek olan bir barajın olması muhtemel bir deprem kuvvetine maruz kalması durumunda düşey ve yatay yönde deformasyon oluşturabileceği görülmüş ve bunların baraj şevlerinde göçmeye sebep olabileceği belirlenmiştir. Bu sebeple baraj analizlerinde statik analizin yanı sıra dinamik analizlerin de yapılması gerektiği ortaya çıkmıştır.

\section{KAYNAKLAR}

[1] ICOLD, International commission on large dams reports, (2016) http://www.icold-cigb.org/GB/publications/bulletins.asp

[2] DSI, Devlet Su İşleri Genel Müdürlüğü istatistik raporları, (2015) http://www.dsi.gov.tr/dsi-resmi-istatistikler

[3] A. Bayraktar, T. Türker, M. Akköse, Ş. Ateş, The Effect of Reservoir Length on Seismic Performance of Gravity Dams to Near-And Far-Fault Ground Motions. Natural Hazards, 52 (2010) 257-275.

[4] M.E. Kartal, Three-dimensional earthquake analysis of roller-compacted concrete dams. Natural Hazards and Earth System Sciences, 12(7) (2012) 2369-2388.

[5] J. Franklin and M. Dusseault, Rock Engineering Applications (McGraw-Hill, New York, 1991).

[6] J. Zhang, J. He, J. Fan, Static and dynamic stability assessment of slopes or dam foundations using a rigid body-spring element method, International Journal of Rock Mechanics and Mining Sciences, 38(8) (2001) 1081-1090.

[7] F. G. Bell, Engineering geology and construction (Spon Press, London, 2004).

[8] M.C. Lia, X.Y. Guoa, J. Shib, Z.B. Zhua, Seepage and stress analysis of anti-seepage structures constructed with different concrete materials in an RCC gravity dam. Water Science and Engineering, 8(4) (2015) 326-334. 
[9] M. Çalamak, M. Selamoğlu, M.A. Yanmaz, Evaluation of rapid drawdown effects on slope stability of earth-fill dams, 4th Hydraulic Structures Symposium, 1 (2015) 278-287. Doi:10.13140/RG.2.1.2084.7448.

[10]C. Houqun, S. Wu, F. Dang, Seismic safety of high arch dams (Elsevier, 2015).

[11]P.A. Lane and D.V. Griffiths, Assessment of stability of slopes under drawdown conditions. Journal of Geotechnical and Geoenvironmental Engineering, 126(5) (2000) 443-450.

[12] A.J. Schleiss and R.M. Boes, Dams and reservoir under changing challenges (CRC Press, London, 2011).

[13]O.C. Zienkiewicz, and R.L. Taylor, The Finite Element Method, 4th edition, Vol. 1: Basic Formulation and Linear Problems (McGraw-Hill, New York, 1987).

[14]R.D. Cook, D.S. Malkus and M.E. Plesha, Concepts and Applications of Finite Element Analysis, 3rd edition (John-Wiley\&Sons, New York, 1989).

[15] İ. Akarsu, Mut bölgesinin jeolojisi. Maden Tetkik Arama Enstitüsü Dergisi, 54 (1960) 3645.

[16]R. Reilinger, S. McClusky, P. Vernant, S. Lawrence, S. Ergintav, R. Cakmak, H. Ozener, F. Kadirov, I. Guliev, R. Stepanyan, M. Nadariya, G. Hahubia, S. Mahmoud, K. Sakr, A. ArRajehi, D. Paradissis, A. Al-Aydrus, M. Prilepin, T. Guseva, E. Evren, A. Dmitrotsa, S.V. Filikov, F. Gomez, R. Al-Ghazzi, G. Karam, GPS constraints on continental deformation in the Africa-Arabia-Eurasia continental collision zone and implications for the dynamics of plate interactions, J. Geophys. Res., 111 (2006) B05411.

[17] DAD, Türkiye ulusal kuvvetli yer hareketi çalışmaları haritaları, Deprem Araştırma Dairesi web sitesi, (2016) http://www.deprem.gov.tr.

[18]J. Woessner, D. Laurentiu, D. Giardini, H. Crowley, F. Cotton, G. Grünthal, G. Valensise, R. Arvidsson, R. Basili, M.B. Demircioglu, S. Hiemer, C. Meletti, R.W. Musson, A.N. Rovida, K. Sesetyan, M. Stucchi, The 2013 European seismic hazard model: key components and results. Bulletin of Earthquake Engineering, 13(12) (2015) 3553-3596.

[19]USGS, Strong-motion recordings from the $\mathrm{ML}=5.5$ Upland, California earthquake of February 28, 1990, open-file report 90-311, (2016).

https://pubs.er.usgs.gov/publication/ofr90311.

[20] T.Z. Yeow, G.A. MacRae, R.P. Dhakal, Wall building stiffness and strength effect on content sliding in Wellington seismic conditions. Earthquake Engineering and Structural dynamics, 46(6) (2016) 1023-1042.

[21] A.S. Chrzanowski, M. Massiéra, Modelling of deformations during construction of a large Earth dam in the La Grande Complex. Technical Sciences, 7 (2004) 109-121.

[22] R.S. Özkuzukıran, Settlement behavior of concrete faced rockfill dams: A Case Study, MSc Thesis in Civil Engineering, (2005) METU.

[23] J. Krahn, Stability modelling with SLOPE/W, printed in Canada (2004).

[24]A.W. Bishop and N. Morgenstern, Stability coefficients for Earth slopes. Geotechnique, 10(4) (1960) 129-153.

[25] N.R. Morgenstern and V.E. Price, The Analysis of the Stability of General Slip Surfaces. Geotechnique, 15 (1965) 79-93. 